\title{
Dynamic Analysis of a High-Speed Railway Train With the Defective Axle Bearing
}

\author{
Jing Liu \\ School of Marine Science and Technology, Northwestern Polytechnical University, Xi'an, 710072, People's Re- \\ public of China. \\ Key Laboratory for Unmanned Underwater Vehicle, Northwestern Polytechnical University, Xi'an, 710072, Peo- \\ ple's Republic of China.
}

Shangkun Du
College of Mechanical Engineering, Chongqing University, Chongqing, 400030, P.R. China.

(Received 4 April 2020; accepted 13 July 2020)

Axle bearings (AXBs) are critical parts for high-speed railway trains (HSTs). Local faults in the AXBs have great influences on the operational dynamics of HSTs. Although some previous works formulated the local faults in single AXB, the vibrations of the whole train system with the defective AXB cannot be described. To overcome this problem, this study conducts a dynamic model for a HST considering a local fault in one AXB. The previous single AXB model cannot formulate the studied case. The impacts caused by the fault in the AXB is defined as a time-dependent force model considering a half-sine type. The road spectrum excitations from the roadbed and rail are formulated by a track irregularities model. The effects of the train speeds and fault sizes on the HST dynamics are introduced. The simulation results from the proposed and previous works are contrasted to show the model validation. The results show that the faults in the AXB will greatly affect the HST dynamics. It depicts that this study can afford a more reasonable approach for understanding the dynamics of HSTs considering the defective AXBs compared to the reported single AXB model.

\section{NOMENCLATURE}

$B_{d}$
$C_{r}$
$C_{1}$
$C_{2}$
$C_{b}$
$c_{i}$
$d_{d e f}$
$D_{p m}$
$f$
$f_{w}$
$f_{c}$
$f_{i}$
$f_{o}$
$f_{b}$
$F_{D}$
$F_{s}$
$F_{T}$
$F_{r}$
$g$
$l$
$K_{c s}$
$K_{r}$
$K_{1}$
$K_{2}$
$K_{b}$
$M_{c}$
$M_{t}$
$M_{w}$
$N_{s}$
$S$
$V$

roller diameter, $\mathrm{mm}$

damping of the rail and roadbed, $\mathrm{N} / \mathrm{m}$

equivalent damping of the first suspension, $\mathrm{KN} \cdot \mathrm{s} / \mathrm{m}$

equivalent damping of the second suspension, $\mathrm{KN} \cdot \mathrm{s} / \mathrm{m}$ damping of the axle bearing, $\mathrm{KN} \cdot \mathrm{s} / \mathrm{m}$ contact angle parameter fault width, $\mathrm{mm}$

bearing pitch diameter, $\mathrm{mm}$ time frequency, $\mathrm{Hz}$ rotational frequency of inner ring, $\mathrm{Hz}$ rotational frequency of cage, $\mathrm{Hz}$ roller passing frequency for inner ring, $\mathrm{Hz}$ roller passing frequency for outer ring, $\mathrm{Hz}$ roller spinning frequency, $\mathrm{Hz}$ dynamic force, $\mathrm{N}$ static force, $\mathrm{N}$ total impact force, $\mathrm{N}$ radial load, $\mathrm{N}$

gravitational acceleration, $\mathrm{m} / \mathrm{s}^{2}$ roller length, $\mathrm{mm}$

contact stiffness between the ring and roller, $\mathrm{N} / \mathrm{m}$ equivalent stiffness of the rail and roadbed, N/m equivalent stiffness of the first suspension, $\mathrm{MN} / \mathrm{m}$ equivalent stiffness of the second suspension, $\mathrm{MN} / \mathrm{m}$ equivalent contact stiffness of the axle bearing, $\mathrm{MN} / \mathrm{m}$ train body mass, ton bogie frame mass, ton wheelset mass, ton

rotational speed of inner ring, $\mathrm{r} / \mathrm{min}$ power spectral density (PSD) value, $\mathrm{mm}^{2} \cdot \mathrm{Hz}$ train speed, $\mathrm{km} / \mathrm{h}$

$\begin{array}{cc}Z & \text { number of rollers } \\ \alpha_{o} & \text { contact angles for outer ring, degree } \\ \alpha_{i} & \text { contact angles for inner ring, degree } \\ \alpha_{f} & \text { contact angles for rib, degree } \\ \Omega & \text { spatial frequency, Hz } \\ \psi_{i} & \text { ith roller angular position, rad } \\ \varepsilon & \text { load distribution parameter } \\ \lambda_{i m p} & \text { impact factor }\end{array}$

\section{INTRODUCTION}

Axle bearings (AXBs) are a critical part for high-speed railway trains (HSTs). Local faults in the AXBs have great influences on the operational dynamics of HSTs, as well as the manufacturing errors. ${ }^{1,2}$ As the most ones, wear between the roller and rings is caused by the lubricating film2. Another one is the spalls due to the sub-surface stresses causing the surface inelastic deformations. ${ }^{3-6}$ The fault may be a surface wear caused by the fatigue, which can grow to the fracture and cracking faults. ${ }^{7,9}$ Numerous derailments in the railroad industry are caused by catastrophic axle bearings. 8,9 When the faults occur in the axle bearings, the impact forces in the bearing should be produced. This phenomenon can greatly affect the vibrations and noises of the axle bearings, as well as the reliability and safety of the HST system. Therefore, the dynamic analysis of the axle bearings with the local faults is very useful for vibration control methods and condition monitoring of the HSTs.

A lot of experimental and numerical approaches were provided to study the vibrations of AXBs. The simulation method can provide a clear and in-depth understanding of the vibrations of axle bearings with and without the faults. Zhai et al. ${ }^{10-12}$ studied the lateral and vertical vibrations from a traintrack-bridge system. Zhu et al. ${ }^{13}$ studied the low-frequency 
vibrations from a metro train. Cantero and Karoumi ${ }^{14}$ analyzed the effects of the train speed, track irregularity cases, and bridge characteristics on the vibrations from a train-trackbridge system. Bokaeian et al. ${ }^{15}$ used a Euler-Bernoulli beam model to study the torsional and bending vibrations of the HST body. Although some works considered the train vibrations including the axle bearings, they did not consider the local faults in the AXBs. This paper will try to overcome this issue.

Many vibration sources can be from the bearings, which include surface waviness, ${ }^{1,16}$ off-sized rollers, ${ }^{17}$ and local faults. ${ }^{18}$ Numerous studies have also been reported to formulate the local faults in different bearings. ${ }^{19}$ For example, Sassi et al., ${ }^{20}$ Khanam et al.., ${ }^{21}$ Liu et al., ${ }^{22,23} \mathrm{Li}$ et al., ${ }^{24}$ Niu et al. ${ }^{25}$ Hou et al., ${ }^{26,27}$ Han et al., ${ }^{28}$ and Kogan et al. ${ }^{29}$ used different analytical methods to study the vibrations of defective bearings. Some works ${ }^{30-32}$ used the finite element methods to study the vibrations of defective bearings. However, the above studies only analyzed the vibrations of single or double general bearing systems. However, the AXB system in the HST is a more complex system than the single or double bearing system. Although Liu et al. ${ }^{33}$ studied the vibrations of AXB considering a local fault, they only considered a simplified single AXB system. Their model cannot be an accurate model to study the vibrations of the complete HST system with the defective AXBs. This issue would be overcome in this work.

This work presented a multi-body dynamic model for a HST system including the AXBs with a local fault. The previous single AXB model cannot formulate the studied case. The train model contains a train body, four wheelsets, two bogie frames, and eight axle bearings. Each wheelset includes two axle bearings. The impacts caused by the fault in the AXB is defined as a time-dependent force model considering a halfsine type. The road spectrum excitations from the roadbed and rail are formulated by a track irregularities model based on the Chinese high-speed low disturbance spectrum. The road spectrum displacement excitations are applied to formulate the excitations produced by the rail and roadbed. The effects of the train speeds and fault sizes on the HST dynamics are introduced. The simulation results from the proposed and previous works are contrasted to show the model validation. The results show that the faults in the AXB will greatly affect the HST dynamics. It depicts that this study can afford a more reasonable method for understanding the dynamics of HSTs considering the defective AXBs compared to the reported single AXB model.

\section{A TRAIN DYNAMIC FORMULATION}

A train dynamic model considering the axle bearings is given in Fig. 1. The train model included a train body, four wheelsets, two bogie frames, and eight axle bearings. Each wheelset included two axle bearings. The above bodies were considered as rigid components in the model. The bogie frames and the wheelset were connected by the first suspensions and axle boxes. The train body was carried by tow bogie frames with the second suspensions at each end. The linear springs with the relative equivalent stiffness and damping are used to formulate the first and second suspensions, as well as the axle bearings. Figure 1(b) shows the whole train dynamic model simulated in the SIMPACK commercial software. Figure 1(c) gives the dynamic model of AXB system. Here, the inner ring and outer ring are connected by the equivalent damping and stiffness elements. (a)

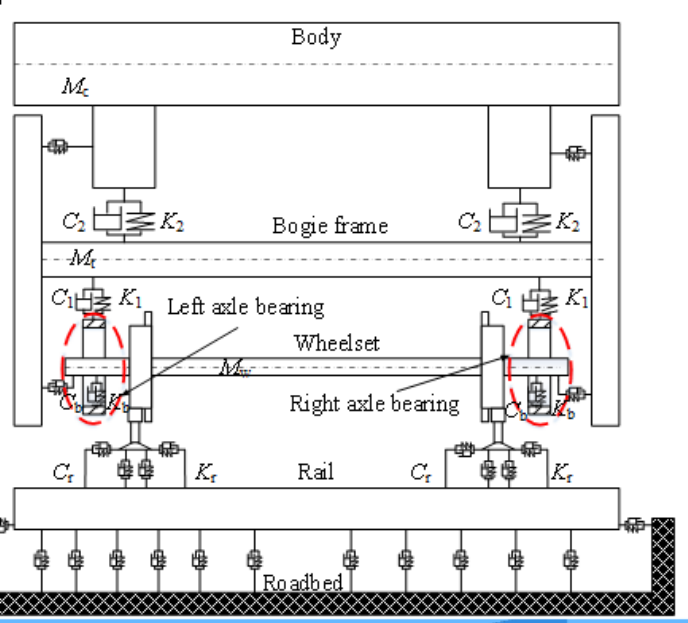

(b)

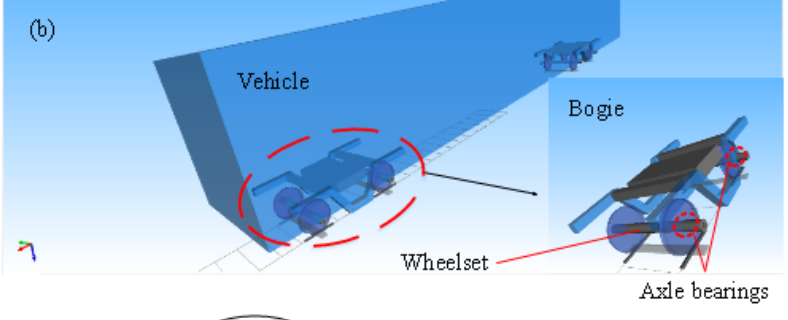

(c)

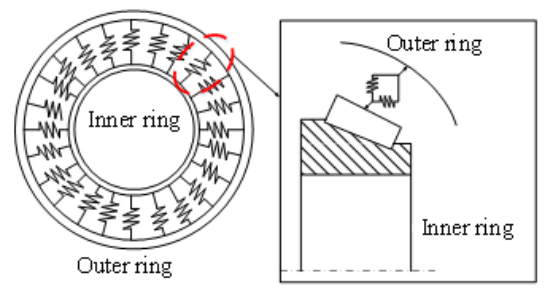

Figure 1. A train dynamic model with the axle bearings. (a) Topological profile of the train, (b) train dynamic model, and (c) dynamic model of the axle bearing.

In Fig. $1, M_{c}=33.766$ ton, $M_{t}=2.4$ ton, and $M_{w}=$ 1.85 ton were the mass of the body, bogie frame, and wheelset, respectively. $K_{r}$ and $C_{r}$ were the equivalent stiffness and damping of the rail and roadbed, whose values were zero here. $K_{1}$ was the equivalent stiffness of the first suspension, whose values were $0.980 \mathrm{MN} / \mathrm{m}, 0.980 \mathrm{MN} / \mathrm{m}$, and $1.176 \mathrm{MN} / \mathrm{m}$ along $x, y$, and $z$ directions, respectively. $C_{1}$ was the equivalent damping of the first suspension, whose values were $9.800 \mathrm{KN} \cdot \mathrm{s} / \mathrm{m}$ along $x, y$, and $z$ directions. $K_{2}$ was the equivalent stiffness of the second suspension, whose values were $0.167 \mathrm{MN} / \mathrm{m}, 0.167 \mathrm{MN} / \mathrm{m}$, and $0.167 \mathrm{MN} / \mathrm{m}$ along $x, y$, and $z$ directions, respectively. $C_{2}$ was the equivalent damping of the second suspension, whose values were $39.2 \mathrm{KN} \cdot \mathrm{s} / \mathrm{m}$ along $x, y$, and $z$ directions. $K_{b}$ and $C_{b}$ were the equivalent contact stiffness and damping of the axle bearing, respectively. The damping of the axle bearing was $2000 \mathrm{~N} / \mathrm{m}$. The used train parameters in the model is given in Table 1.

\subsection{Track Irregularities Model}

A typical Chinese high-speed low disturbance spectrum model was used to formulate the track excitations according to the analysis in Ref., ${ }^{12}$ as shown in Fig. 2, whose expression is:

$$
S(\Omega)=\frac{A\left(\Omega^{2}+B \Omega+C\right)}{\left(\Omega^{4}+D \Omega^{3}+F \Omega+G\right)} ;
$$




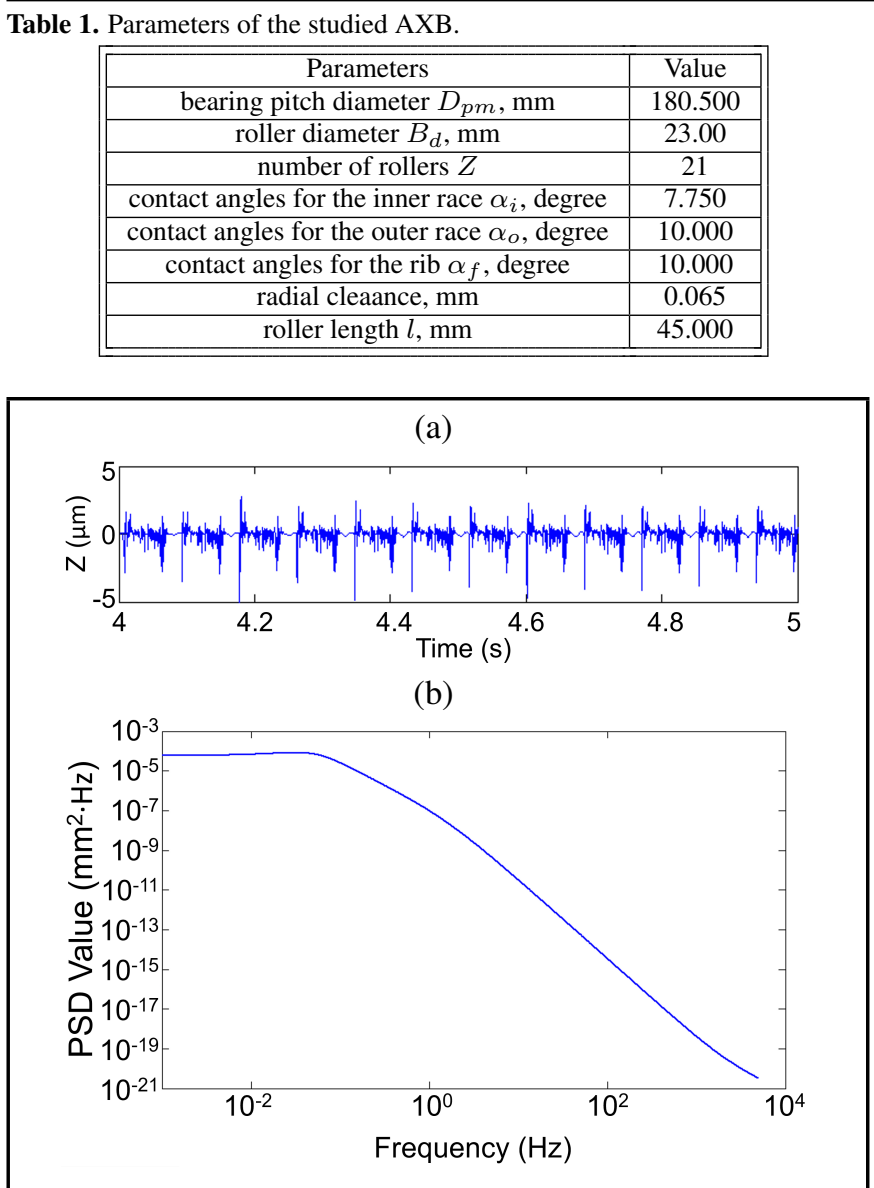

Figure 2. (a) Random displacement excitation and (b) its PSD of the track longitudinal irregularity.

where $S$ was the power spectral density (PSD) value $\left(\mathrm{mm}^{2} \cdot \mathrm{Hz}\right) ; \quad \Omega$ was the spatial frequency, in which $\Omega=2 \pi f / V$, where $f$ and $V$ were the time frequency and train speed; $A, B, C, D, E, F$, and $G$ denoted the characteristic parameters for PSD, whose values were $0.6650,-1.4357,0.537,0.8138,1.9123,-0.1234$, 0.0063 , respectively.

\subsection{Impact Force Model}

According to the results in Ref., ${ }^{22}$ when the fault occurs in the bearing components, the time-varying impact force between the mating components should be produced as shown in Fig. 3. The total impact force can be written as 22 :

$$
F_{T}=F_{S}+F_{D}
$$

where $F_{s}$ was the static force, which was given as:

$$
F_{S}=\frac{5 F_{r}}{Z \cos \alpha}\left(1-\frac{1-\cos \psi_{i}}{2 \varepsilon}\right)^{10 / 9} ;
$$

where $F_{r}, Z, \varepsilon \psi_{i}$, were $\alpha$ the radial load, number of the roller, and load distribution parameter, $i$ th roller angular position, and contact angle of $\mathrm{AXB}$. Moreover, $F_{D}$ was the dynamic force, which was written as:

$$
F_{D}=F_{S}\left[1+\lambda_{i m p} \frac{10}{28} g B_{d}\left(\frac{d_{d e f}}{B_{d}}\right)^{2}\right]
$$

where $\lambda_{i m p}$ was the impact factor, whose value is $0.96 ;^{22} d_{d e f}$ was the fault width; $B_{d}$ was the roller diameter; and $g$ was the

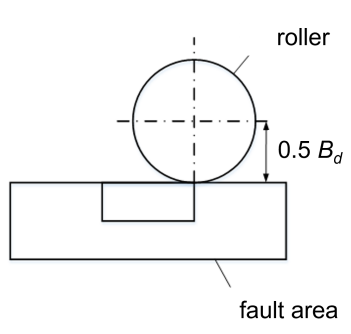

Position \#1

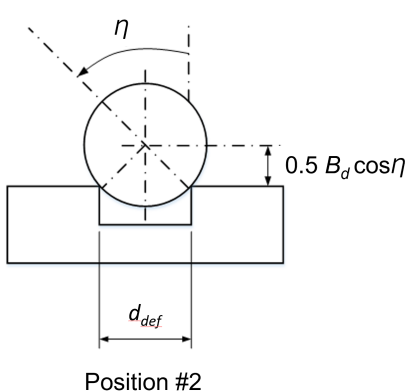

Position \#2
Figure 3. Contact relation between the fault and roller.

gravitational acceleration. The static force was produced by the applied radial load on the bearing. The dynamic force was produced by the impacts between the roller and fault area.

\subsection{Contact Stiffnes Formulation}

According to Palmgren's method, the contact stiffness between one roller and rings was ${ }^{33}$ :

$$
K_{c s}=8.06 \times 10^{4} l^{0.89}\left[1+c_{i}^{0.9} \cos \left(\alpha_{o}-\alpha_{i}\right)\right]^{-10 / 9}
$$

where $c_{i}$ was the given as:

$$
c_{i}=\frac{\sin \left(\alpha_{o}+\alpha_{f}\right)}{\sin \left(\alpha_{i}+\alpha_{f}\right)} .
$$

According to the parameters in Table 1, the contact stiffness is $1.043 \times 109 \mathrm{~N} / \mathrm{m}$.

\section{RESULTS AND DISCUSSION}

This section will discuss the effects of the fault location and sizes on the vibrations of HST.

\subsection{Model Validation}

Figure 4 introduces the acceleration spectra of defective AXB considering the outer ring, inner ring, and roller fault cases, respectively. Here, the HST speed is $350 \mathrm{~km} / \mathrm{h}$; and the fault width is $5 \mathrm{~mm}$. In Fig. 4(a), the peak frequencies located at the $n f_{o}\left(f_{o}=307.60 \mathrm{~Hz} \approx 308.18 \mathrm{~Hz}\right.$, and $n=1,2$, and $3, \ldots)$. In Fig. 4(b), the peak frequencies located at the $n f_{i}$ $\left(f_{i}=398.10 \mathrm{~Hz} \approx 398.16 \mathrm{~Hz}\right)$; moreover, the modulation frequency is $33.7 \mathrm{~Hz}=f_{s}=33.64 \mathrm{~Hz}$, where $f_{s}$ is the shaft frequency. In Fig. 4(c), the peak frequencies located at the $2 n f_{b}$ $\left(2 f_{b}=259.00 \mathrm{~Hz}\right.$, and $\left.f_{b}=129.55 \mathrm{~Hz} \approx 129.50 \mathrm{~Hz}\right)$; moreover, the modulation frequency is $14.00 \mathrm{~Hz} \approx f_{c}=14.68 \mathrm{~Hz}$, where $\mathrm{fc}$ is the cage frequency. The calculation methods of the above frequencies have been listed in Appendix A. Comparisons of the characteristic frequencies between the theoretical method in Ref. ${ }^{12}$ and proposed model are listed in Table 3. The results depict that their differences are $0.20 \%, 0.02 \%$, and $0.04 \%$ for the three fault cases, respectively, which can afford some model validation.

\subsection{Effects Of Outer Ring Fault Width and HST Speed on Dynamics}

The effect of the outer ring fault $(W=5 \mathrm{~mm})$ on the bogie frame acceleration and contact force in the AXB of the healthy 
Table 2. Comparisons between the theoretical and simulation results.

\begin{tabular}{|c|c|c|c|c|}
\hline \hline Case & Parameter & Theoretical result $(\mathrm{Hz})$ & Simulation result $(\mathrm{Hz})$ & Difference $(\%)$ \\
\hline 1 & roller passing frequency for outer ring, $f_{o}$ & 308.18 & 307.60 & 0.20 \\
\hline 2 & roller passing frequency for inner ring, $f_{i}$ & 398.16 & 398.10 & 0.02 \\
\hline 3 & roller spinning frequency, $f_{b}$ & 129.50 & 129.55 & 0.04 \\
\hline
\end{tabular}

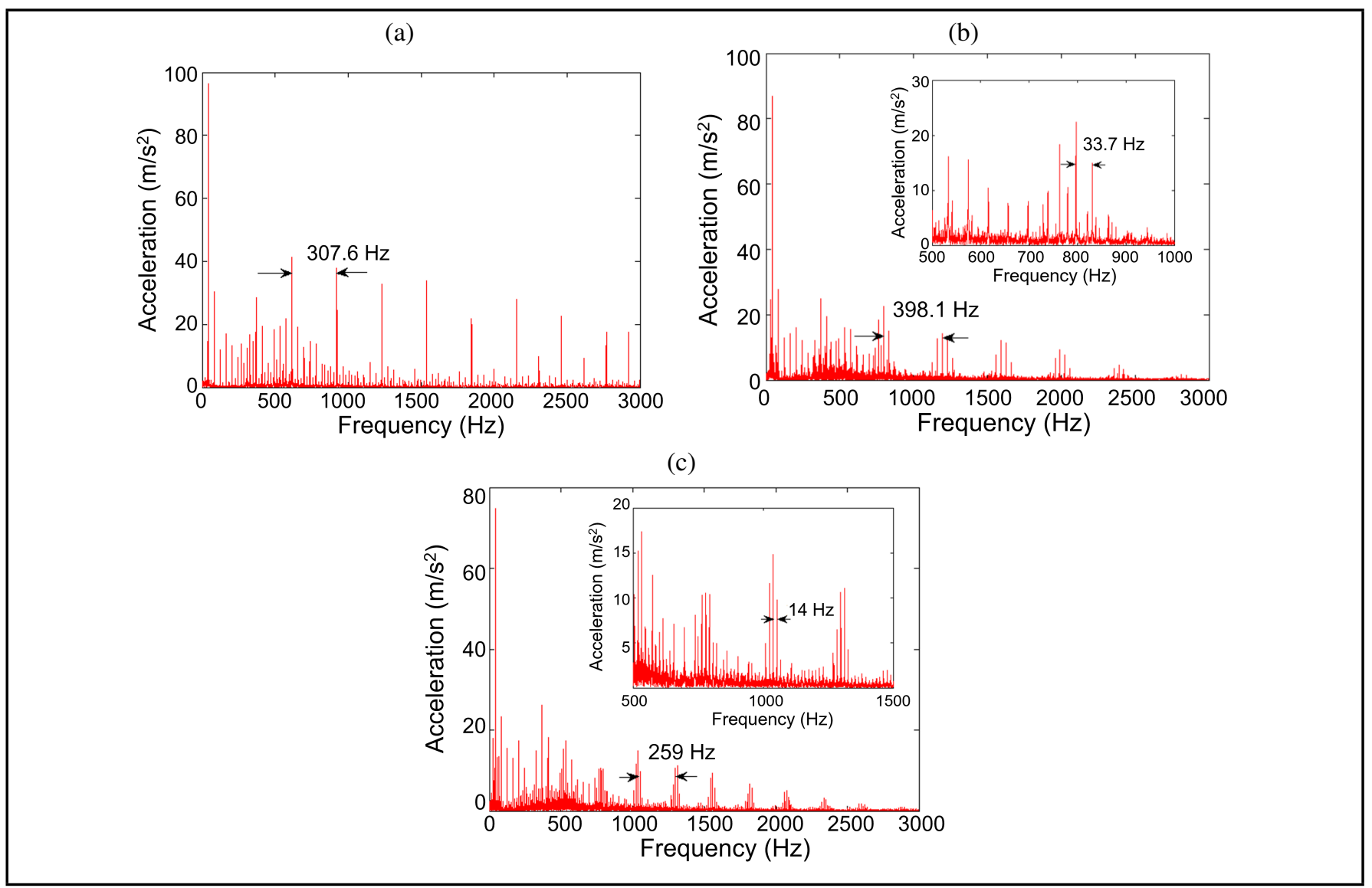

Figure 4. Acceleration spectra of $\mathrm{AXB}$ with (a) the outer ring, (b) inner ring, and (c) roller fault cases.

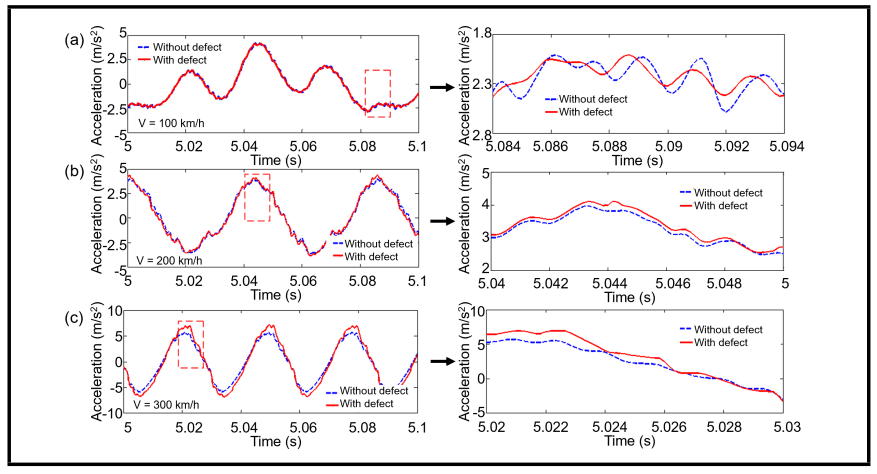

Figure 5. Effect of the outer ring fault on the bogie frame acceleration when the HST speed is (a) $100 \mathrm{~km} / \mathrm{h}$, (b) $200 \mathrm{~km} / \mathrm{h}$, and (c) $300 \mathrm{~km} / \mathrm{h}$, respectively.

and unhealthy HST systems is shown in Figs. 5 and 6, respectively. It seems that the outer ring fault has small effect on the waveform and amplitude of the bogie frame acceleration and contact force in the AXB. Some additional impulse produced by the outer ring fault can be observed in the bogie frame acceleration and contact force in the AXB. The amplitudes of the bogie frame acceleration and contact force in the AXB of the unhealthy HST system are larger than those of the healthy HST system.

The effect of the outer ring fault on the maximum and RMS values of the wheelset acceleration is shown in Fig. 7. The

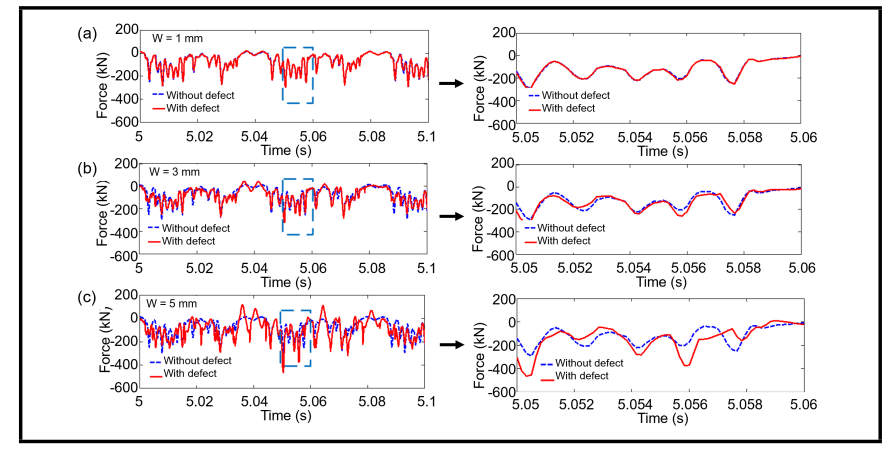

Figure 6. Effect of the outer ring fault on the contact force in the defective AXB when its width is (a) $1 \mathrm{~mm}$, (b) $2 \mathrm{~mm}$, and (c) $3 \mathrm{~mm}$, respectively.

vibration of the wheelset increases with the increment of the outer ring fault for different HST systems. The wheelset vibration increases with the increment of HST speed too. As given in Fig. 7, when the HST speed is less than or equal to $200 \mathrm{~km} / \mathrm{h}$, the effect of the outer ring fault on the wheelset vibration is great for different train speed cases; however, when the HST speed is more than $200 \mathrm{~km} / \mathrm{h}$, the effect of the outer ring fault is small for different train speed cases. It seems that the effect of the outer ring fault on the wheelset vibration is larger than the vibration caused by the track excitations for when the train speed is less than or equal to $200 \mathrm{~km} / \mathrm{h}$. However, the effect of the outer ring fault on the wheelset vibration is less than the vi- 


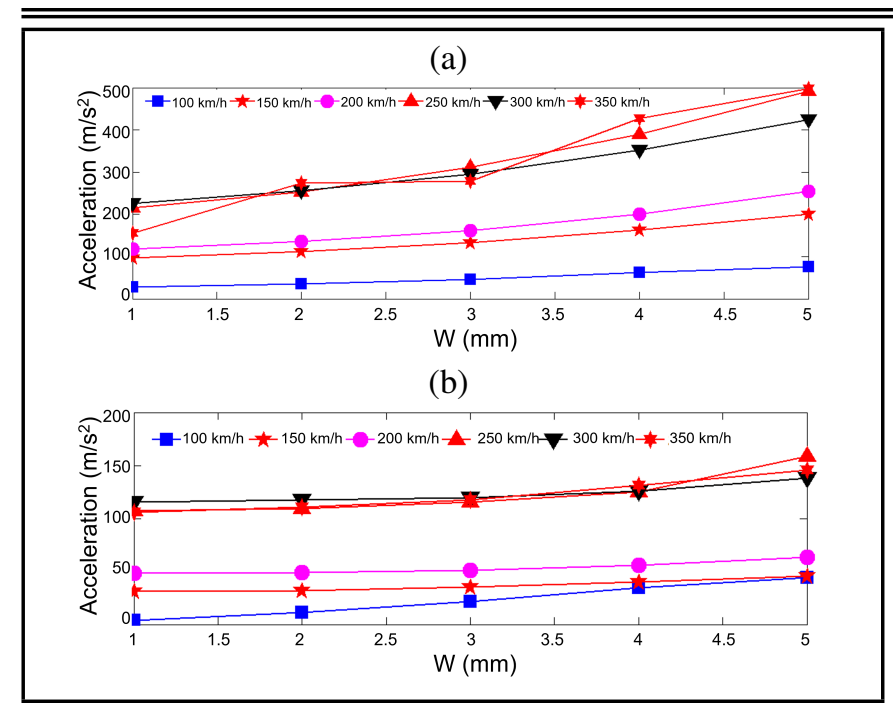

Figure 7. Effect of the outer ring fault on the (a) maximum and (b) RMS values of the wheelset acceleration.

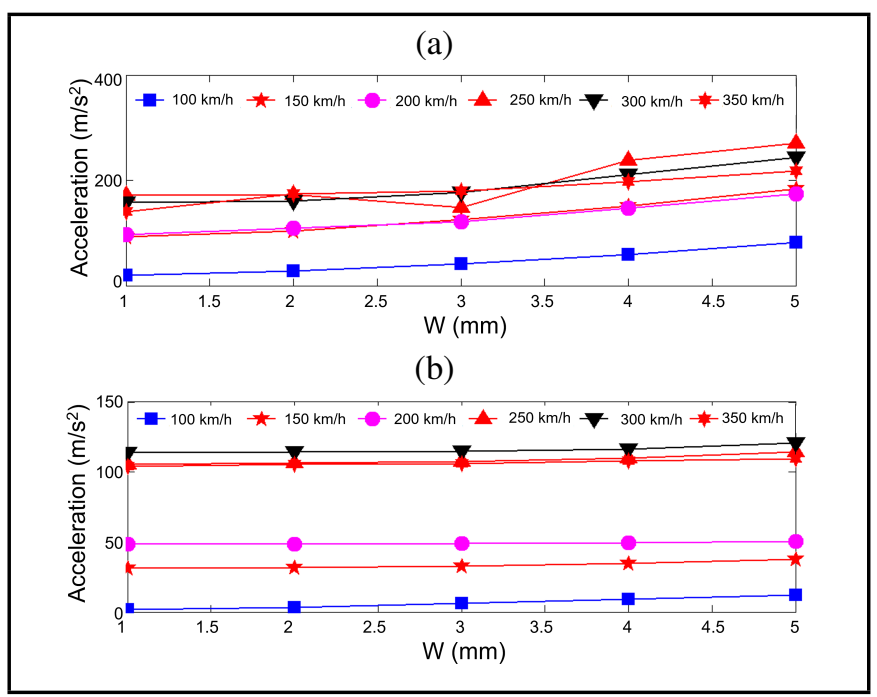

Figure 8. Effect of the inner ring fault on the (a) maximum and (b) RMS values of the wheelset acceleration.

bration caused by the track excitations for when the HST speed is larger $200 \mathrm{~km} / \mathrm{h}$.

\subsection{Effects of Inner Ring Fault Width and HST Speed on The Dynamics}

The effect of the inner ring fault on the maximum and RMS values of the wheelset acceleration is shown in Fig. 8. The wheelset vibration increases with the increment of the inner ring fault for different HST systems. The wheelset vibration increases with the increment of the HST speed too. As given in Fig. 8, when the train speed is less than or equal to $150 \mathrm{~km} / \mathrm{h}$, the effect of the inner ring fault on the wheelset vibration is great for different train speed cases; however, when the train speed is more than $150 \mathrm{~km} / \mathrm{h}$, the effect of the inner ring fault is small for different HST speed cases. It seems that the effect of the inner ring fault on the wheelset vibration is larger than the vibration caused by the track excitations when the HST speed is less than or equal to $150 \mathrm{~km} / \mathrm{h}$. However, the effect of the inner ring fault on the wheelset vibration is less than the vibration caused by the track excitations for when the HST speed is larger $150 \mathrm{~km} / \mathrm{h}$. (a)

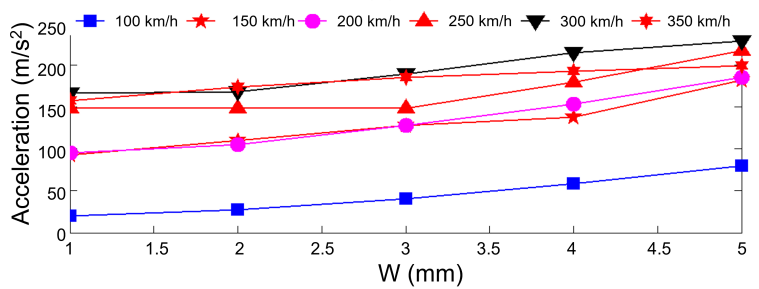

(b)

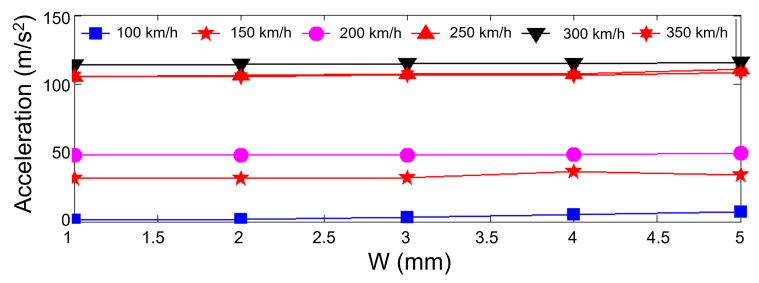

Figure 9. Effect of the roller fault on the (a) maximum and (b) RMS values of the wheelset acceleration.

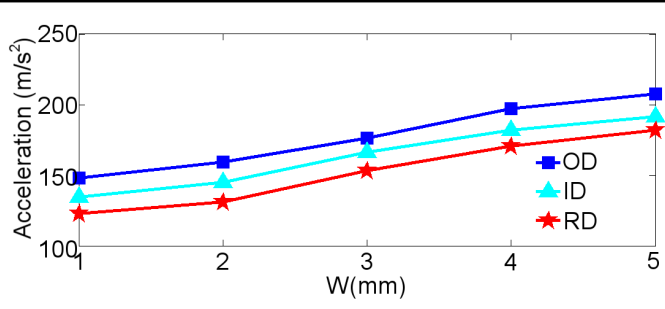

Figure 10. Effect of the fault location on the maximum value of the wheelset acceleration. (OD, ID, and RD denote the outer ring, inner ring, and roller fault cases, respectively.)

\subsection{Effects of Roller Fault Width and HST Speed on The Dynamics}

The effect of the roller fault on the maximum and RMS values of the wheelset acceleration is shown in Fig. 9. The wheelset vibration increases with the increment of the roller fault for different HST systems. The wheelset vibration also increases with the increment of the HST speed. As given in Fig. 9, when the HST speed is less than or equal to $150 \mathrm{~km} / \mathrm{h}$, the effect of the roller fault on the wheelset vibration is greater for different HST speed cases; however, when the HST speed is more than $150 \mathrm{~km} / \mathrm{h}$, the effect of the roller fault is smaller for different HST speed cases. It seems that the effect of the roller fault on the wheelset vibration is larger than the vibration caused by the track excitations when the HST speed is less than or equal to $150 \mathrm{~km} / \mathrm{h}$. However, the effect of the roller fault on the wheelset vibration is less than the vibration caused by the track excitations for when the HST speed is larger $150 \mathrm{~km} / \mathrm{h}$.

\subsection{Effect of The Fault Location on The Accelerations}

Figure 10 plots the effect of the fault location on the maximum value of wheelset acceleration. The HST speed is 100 $\mathrm{km} / \mathrm{h}$. The fault widths are $1 \mathrm{~mm}$ to $5 \mathrm{~mm}$, respectively. In Fig. 10, the effect of the outer ring fault on the wheelset vibration is larger than those of the inner ring and roller fault cases; the effect of the inner ring fault on the wheelset vibration is larger than that of the roller fault. Moreover, it seems that the wheelset vibration increases with the increment of the outer ring, inner ring, and roller ring fault cases. 


\section{CONCLUSIONS}

This study presents a dynamic model of a HST considering a local fault in one AXB. The previous single AXB model cannot formulate the studied case. The impacts caused by the fault in the AXB is defined as a time-dependent force model considering a half-sine type. The road spectrum excitations from the roadbed and rail are formulated by a track irregularities model. The effects of the train speeds and fault sizes on the HST dynamics are introduced. The simulation results from the proposed and previous works are contrasted to show the model validation. The results show that the faults in the AXB will greatly affect the HST dynamics. The bearing fault has a small effect on the waveform and amplitude of the bogie frame acceleration and contact force in the AXB. Some additional impulses produced by the outer ring fault can be observed in the bogie frame acceleration and contact force in the AXB. The amplitudes of the bogie frame acceleration and contact force in the AXB of the unhealthy HST system are larger than those of the healthy HST system. The wheelset vibration increases with the increment of the roller fault for different HST systems. The wheelset vibration increases with the increment of the HST speed too. When the HST speed is a smaller one, the effect of the bearing fault on the wheelset vibration is greater than that caused by the track excitations. When the HST speed is a larger one, the effect of the bearing fault is smaller than that caused by the track excitations. The effect of the outer ring fault on the wheelset vibration is larger than those of the inner ring and roller fault cases; the effect of the inner ring fault on the wheelset vibration is larger than that of the roller fault. It depicts that this study can provide a more reasonable method for understanding the dynamics of HST considering the local faults in the AXBs compared to the reported single AXB model.

According the current analysis, a reasonable equivalent stiffness and damping of the first and second suspensions can reduce the influence of impact caused by the faults in the bearings on the HST system. Since the authors' test conditions cannot support the relative experiment. Thus, the simulation results from the proposed method are compared with those from the method in Ref. ${ }^{34}$ The authors will do their best to obtain some experimental data in their future works.

\section{ACKNOWLEDGEMENT}

The authors are grateful for National Natural Science Foundation of China under Contract No. 51975068; and the Fundamental Research Funds for the Central Universities under contract No. 3102020HHZY030001.

\section{REFERENCES}

1 Lynagh N, Rahnejat H, Ebrahimi M, et al. Bearing induced vibration in precision high speed routing spindles. International Journal of Machine Tools and Manufacture, 40(4), 561-577, (2000). https://dx.doi.org/10.1016/S08906955(99)00076-0

2 Gohar R. Elastohydrodynamics. 2nd ed. London: World Scientific, 404-406, (2001).

3 Gohar R and Rahnejat H. Fundamentals of tribology. 2nd ed. London: Imperial College Press, 147, (2012).

${ }^{4}$ Liu J, Shi Z, Shao Y. Vibration characteristics of a ball bearing considering point lubrication and nonuniform surface waviness. International Journal of Acoustics and Vibration, 23(3), 355-361 (2018). https://dx.doi.org/10.20855/ijav.2018.23.31249

5 Johns-Rahnejat PM and Gohar R. Point contact elastohydrodynamic pressure distribution and sub-surface stress field, Tri-annual conference on multi-body dynamics: monitoring and simulation techniques, Bradford, UK, (1997).

${ }^{6}$ Liu J, Shao Y. Dynamic modeling for rigid rotor bearing systems with a localized defect considering additional deformations at the sharp edges. Journal of Sound and Vibration, 398(23), 84-102 (2017). https://dx.doi.org/10.1016/j.jsv.2017.03.007

7 Amini A, Entezami M and Papaelias M. Onboard detection of railway axle bearing defects using envelope analysis of high frequency acoustic emission signals. Nondestruct Test Eval, 6, 8-16, (2016). https://dx.doi.org/10.1016/j.csndt.2016.06.002

8 Choe H C, Wan Y, Chan A K. Neural pattern identification of railroad wheel-bearing faults from audible acoustic signals: comparison of FFT, CWT, and DWT features. SPIE Proceedings on Wavelet Applications IV, International Society for Optics and Photonics, 3078, 480-497 (1997). https://dx.doi.org/10.1117/12.271772

9 Papaelias M, Amini A, Huang Z, et al. Online condition monitoring of rolling stock wheels and axle bearings. Proc IMechE, Part F: J Rail Rapid Transit, 230, 709-723 (2016). https://dx.doi.org/10.1177/0954409714559758

10 Zhai W M, Wang K Y, Cai C. Fundamentals of vehicle-track coupled dynamics. Vehicle System Dynamics, 47(11), 1349-1376 (2009). https://dx.doi.org/10.1080/00423110802621561

11 Zhai W M, Xia H, Cai C, Gao M, Li X, Guo X, Zhang N, Wang K Y. High-speed train-track-bridge dynamic interactions - Part I: theoretical model and numerical simulation. International Journal of Rail Transportation, 1(1-2), 3-24 (2013). https://dx.doi.org/10.1080/23248378.2013.791498

12 Z. Chen, Z. Zhou, W. Zhai, K. Wang. Improved analytical calculation model of spur gear mesh excitations with tooth profile deviations. Mechanism and Machine Theory, 149, 103838 (2020). https://dx.doi.org/10.1016/j.mechmachtheory.2020.103838

13 Zhu S, Yang J, Yan $H$, et al. Low-frequency vibration control of floating slab tracks using dynamic vibration absorbers. Vehicle System Dynamics, 53(9), 1296-1314 (2015). https://dx.doi.org/10.1080/00423114.2015.1046460

14 Cantero D, Karoumi R. Numerical evaluation of the midspan assumption in the calculation of total load effects in railway bridges. Engineering Structures, 107, 1-8, (2016). https://dx.doi.org/10.1016/j.engstruct.2015.11.005

15 Bokaeian V, Rezvani M A, Arcos R. The coupled effects of bending and torsional flexural modes of a high-speed train car body on its vertical ride quality. Proceedings of the Institution of Mechanical Engineers, Part K: Journal of Multi-body Dynamics, 1464419319856191, (2019). https://dx.doi.org/10.1177/1464419319856191 
16 Liu J, Shao Y M. Vibration modelling of nonuniform surface waviness in a lubricated roller bearing. Journal of $\mathrm{Vi}$ bration and Control, 23(7), 1115-1132 (2017).

17 Vafaei S, Rahnejat $\mathrm{H}$ and Aini R. Vibration monitoring of high speed spindles using spectral analysis techniques. International Journal of Machine Tools and Manufacture, 42, 1223-1234 (2002). https://dx.doi.org/10.1016/S08906955(02)00049-4

18 Liu J, Shao Y, Lim T C. Vibration analysis of ball bearings with a localized defect applying piecewise response function. Mechanism and Machine Theory, 56, 156-169 (2012). https://dx.doi.org/10.1016/j.mechmachtheory.2012.05.008

19 Liu J, Shao Y. Overview of dynamic modelling and analysis of rolling element bearings with localized and distributed faults. Nonlinear Dynamics, 93(4), 1765-1798 (2018). https://dx.doi.org/10.1007/s11071-018-4314-y

20 Sassi S, Badri B, Thomas M. A numerical model to predict damaged bearing vibrations. Journal of Vibration and Control, 13(11), 1603-1628 (2007). https://dx.doi.org/10.1177/1077546307080040

21 Khanam S, Tandon N, Dutt J K. Multi-event excitation force model for inner race defect in a rolling element bearing. Journal of Tribology, 138(1), 011106 (2016). https://dx.doi.org/10.1115/1.4031394

22 Liu J, Shao Y. An improved analytical model for a lubricated roller bearing including a localized defect with different edge shapes. Journal of $\mathrm{Vi}$ bration and Control, 24(17), 3894-3907 (2018). https://dx.doi.org/10.1177/1077546317716315

23 Liu J. A dynamic modelling method of a rotorroller bearing-housing system with a localized fault including the additional excitation zone. Journal of Sound and Vibration, 469, 115144, (2020). https://dx.doi.org/10.1016/j.jsv.2019.115144

${ }^{24} \mathrm{Li} \mathrm{X}, \mathrm{Yu} \mathrm{K}, \mathrm{Ma} \mathrm{H}$, Cao L, Luo Z, Li H, \& Che L. Analysis of varying contact angles and load distributions in defective angular contact ball bearing. Engineering Failure Analysis, 91, 449-464 (2018). https://dx.doi.org/10.1016/j.engfailanal.2018.04.050

25 Niu L, Cao H, He Z, et al. A systematic study of ball passing frequencies based on dynamic modeling of rolling ball bearings with localized surface defects. Journal of Sound and Vibration, 357, 207-232 (2015). https://dx.doi.org/10.1016/j.jsv.2015.08.002

26 Hou L, Chen H, Chen Y, Lu K, Liu Z. Bifurcation and stability analysis of a nonlinear rotor system subjected to constant excitation and rub-impact. Mechanical Systems and Signal Processing, 125, 65-78 (2019). https://dx.doi.org/10.1016/j.ymssp.2018.07.019

27 Yang R, Jin Y, Hou L, et al. Advantages of pulse force model over geometrical boundary model in a rigid rotor-ball bearing system. International Journal of Non-Linear Mechanics, 102, 159-169 (2018). https://dx.doi.org/10.1016/j.ijnonlinmec.2018.03.011

28 Han Q, Ding Z, Xu X, et al. Stator current model for detecting rolling bearing faults in induction motors using magnetic equivalent circuits. Mechanical Sys- tems and Signal Processing, 131, 554-575 (2019). https://dx.doi.org/10.1016/j.ymssp.2019.06.010

29 Kogan G, Klein R, Bortman J. A physics-based algorithm for the estimation of bearing spall width using vibrations. Mechanical Systems and Signal Processing, 104, 398-414 (2018). https://dx.doi.org/10.1016/j.ymssp.2017.11.011

30 Liu J, Shao Y, Zuo M J. The effects of the shape of localized defect in ball bearings on the vibration waveform. Proceedings of the Institution of Mechanical Engineers, Part K: Journal of Multi-body Dynamics, 227(3), 261-274 (2013). https://dx.doi.org/10.1177/1464419313486102

31 Liu J, Shao Y. A numerical investigation of effects of defect edge discontinuities on contact forces and vibrations for a defective roller bearing. Proceedings of the Institution of Mechanical Engineers, Part K: Journal of Multi-body Dynamics, 230(4), 387-400 (2016). https://dx.doi.org/10.1177/1464419315615451

32 Liu Y, Liu H, Fan B. Numerical analysis on the static-dynamic coupling influences of parallelism flaw in disc-rod rotor ball bearing system. Proceedings of the Institution of Mechanical Engineers, Part K: Journal of Multi-body Dynamics, 232(1), 103-112 (2018). https://dx.doi.org/10.1177/1464419317710886

33 Liu H, Wang L, Li Y. Simulation of rail wheel axle bearing vibration due to local damages on outer races. Proceedings of the Institution of Mechanical Engineers, Part K: Journal of Multi-body Dynamics, 233(2), 429-440, (2019). https://dx.doi.org/10.1177/1464419318778253

34 Palmgren A. Ball and roller bearing engineering, 3rd ed., Burbank, Philadelphia, (1959).

35 Harris T A, Kotzalas M N. Rolling bearing analysisessential concepts of bearing technology, 5 th ed. Taylor and Francis, (2007).

\section{APPENDIX A}

According to the method in Ref., ${ }^{1}$ the rotational frequency of inner ring is:

$$
f_{w}=\frac{N_{s}}{60}
$$

where $N_{s}$ is the rotational speed of inner ring. The rotational frequency of cage is:

$$
f_{c}=\frac{f_{i}}{2}\left[1-\frac{B_{d}}{D_{p m}} \cos \alpha\right]+\frac{f_{o}}{2}\left[1+\frac{B_{d}}{D_{p m}} \cos \alpha\right] ;
$$

where $\alpha$ is the equivalent contact angel, which is equal to $\alpha_{o}{ }^{35}$ The roller passing frequency for inner ring is:

$$
f_{i}=\frac{f_{w}}{2}\left[1+\frac{B_{d}}{D_{p m}} \cos \alpha\right] \text {. }
$$

The roller passing frequency for outer ring is:

$$
f_{o}=\frac{f_{w}}{2}\left[1-\frac{B_{d}}{D_{p m}} \cos \alpha\right] .
$$

The roller spinning frequency is:

$$
f_{b}=\frac{f_{w} D_{p m}}{2 B_{d}}\left[1-\left(\frac{B_{d}}{D_{p m}} \cos \alpha\right)^{2}\right]
$$

